\title{
Sir Charles Bell and the anatomy of expression
}

\author{
I S L LOUDON
}

The Reverend William Bell of Edinburgh (died 1779) had four distinguished sons. Two (George and Robert) became professors of law. John (1763-1820), who was Edinburgh's most distinguished surgeon at the turn of the eighteenth century, was a brilliant teacher and writer and an excellent draughtsman. But the youngest, Sir Charles Bell (1774-1842), was the most famous, remembered today for his contributions to neurology and the eponym "Bell's palsy." His father died when he was 5, and he said, "I received no education but from my mother" because he hated school and learning by rote. In adult life he said he had always distrusted his memory and never could "venture on a quotation either in conversation or public discourse." Despite this he was a brilliant lecturer and, in apparent contradiction, said he could write his lecture notes on a thumb nail. ${ }^{1-3}$

His great love, which remained throughout his life, was a love of drawing. His mother, from whom both Charles and John probably inherited their outstanding artistic talent, had the good sense, despite family poverty, to employ as drawing master the painter David Allan-an odd little man with crooked legs, an ill-shaped nose, and a thatch of hair but a sharp liveliness-who gave his pupil studies from the antique and Raphael's cartoons to copy. Charles Bell adored him: "There was sunshine in the afternoon when he came," he wrote later, "He was at all times wont to salute me, 'Ha! brother Brush, let's see what you have been doing." ",

\section{Art and anatomy}

At the age of 18 Charles was apprenticed to his brother John, who two years earlier had opened a private school of anatomy and surgery. There, Charles began the long series of beautiful anatomical illustrations in which his love of art and anatomy shines through. The usual woodcuts and copperplate illustrations of anatomical texts at that time were poor: "Bones were drawn like hedge-stakes and muscles like dish-clouts." 5 Both the brothers, but Charles in particular, brought a conscious and deliberate artistry and sometimes a certain quirkiness to anatomical illustration. For instance, in a drawing of a dissection of the leg to show the arteries the dissected leg stands upright with the foot oddly arched over a large syringe. ${ }^{6}$ In another, of an abdominal dissection, the subject has his arms stretched high over his head and the wrists tied as if to suggest, gruesomely, that he had been strung up alive. ${ }^{7}$ In two dissections of the same subject the young features, curly hair, and curled and pointed moustache were lovingly recorded, ${ }^{78}$ while in a drawing of a dissected hand the index finger rests lightly on a closed book. ${ }^{6}$ Minute detail, such as the ligatures and pins used for holding back skin flaps and muscles, are shown with the shadows they cast.

Drawing is itself a form of exploration and discovery, a kind of visual dissection, whether the subject is an anatomical dissection, a portrait, or a landscape. It is this that makes drawing exciting, and Charles Bell's works are memorable in a way that is rare indeed in anatomy. The best of them, especially those of the limbs designed to demonstrate the blood vessels and peripheral nerves, show highly original powers of composition and are drawings of great beauty. ${ }^{910}$ Wellcome Unit for the History of Medicine, University of Oxford,
Oxford OX2 6PE

I S L LOUDON, DM, FRCGP, Wellcome research fellow

\section{From Scotland to London}

Charles Bell loved Scotland. He might well have stayed in Edinburgh but for his tempestuous brother John, who loved a fight and was locked in a public quarrel of unparalleled ferocity with Dr James Gregory (1753-1821), professor of the practice of medicine. Charles was a man of kindlier, more gentle disposition. He took the advice of his brother George (with whom he corresponded all his life) and left for London in 1804. Scottish graduates were often unpopular south of the border, and on his arrival Charles was greeted sourly by a London surgeon, who told him they could manufacture their own raw material and if he had experienced difficulties in Edinburgh he would have more in London. Nevertheless, he stayed, and several well-known medical men supported him, including Astley Cooper and most of all William Lynn, a surgeon at the Westminster Hospital, who realising his potential ability gave encouragement by saying, "They have got the scent of you, they are looking sharp after you. D- it Sir, they think you are going to knock us all out!" (letter dated 1 January 1805). ${ }^{4}$ But it was a slow process. During the first year in London he lectured to medical students on surgery (earning $£ 82$ ) and to artists on anatomy (earning $£ 25$ ) (letter dated 5 February 1806). ${ }^{4}$ Through the latter he was encouraged to complete a most unusual book he had started in Edinburgh, Essays on the Anatomy of the Expression in Painting. ${ }^{11}$ The illustrations in this issue of the $B M F$ come from his own annotated copy of the first edition: in later editions the text was expanded and the number of drawings reduced.

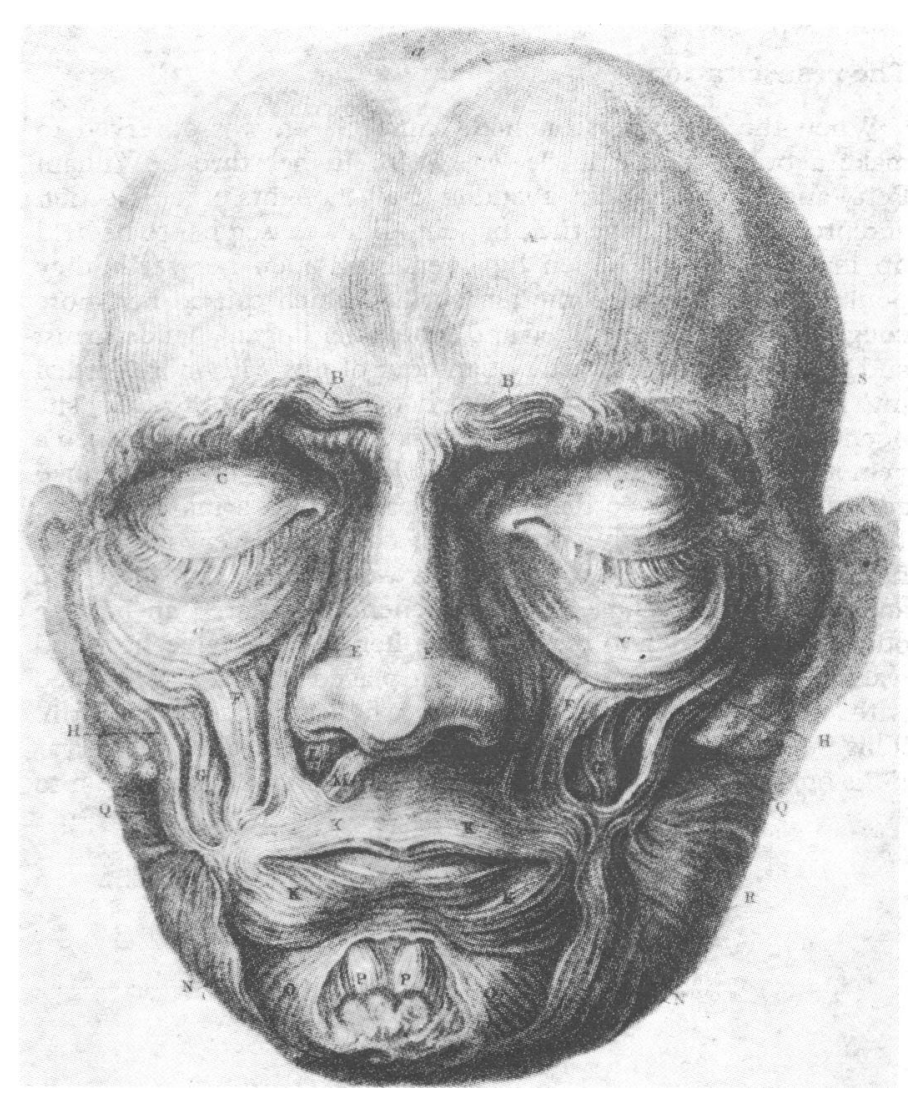

Muscles of the face ( $p$ 157). This is one of Bell's most famous drawings and a work of great beauty. Charles Bell was probably happier drawing dissections
than anything else. 


\section{Expression, emotion, and action}

The book has a philosophical turn to it. His aim was not just to convince painters of the value of a study of anatomy but to demonstrate his belief that "expression is to passion what language is to thought." $\mathrm{He}$ deplored the sole use of antiques and models ("academy figures-usually soldiers or mechanics") because they displayed posture not action. He attempted to analyse expression in terms of the action of certain muscles, and if the attempt was at best partially successful he made many illuminating observations. Thus he pleaded for an intensive study of the expressions of infants, believing that they displayed a special force and purity not seen in adults and also that they exemplified the way facial expressions can generate as well as express the emotions they display. ${ }^{12} \mathrm{He}$ also wrote on expression in animals, believing that man had certain muscles, absent in other animals, whose sole function was the rich variety of facial expression of which man is capable. He gave as examples the "corrugator supercillii, which arises from the frontal bone near the union with the nasal bones and is inserted into the skin of the eyebrow. It knits the eyebrows ..." (hence supercilious) and the "depressor anguli oris, a muscle I have not found in any other animal .... it produces that arching of the lip so expressive of contempt, hatred, jealousy."13 Perhaps the book's chief merit lies in the illustrations. Charles Bell could excel not only in the detailed meticulous drawings that must have taken hours to complete but also in the quick free-flowing sketch. Unfortunately, nowhere in either the first or later editions is it acknowledged that some of the drawings were donated by artist friends. The miniaturist, Saunders, executed the laughing head and David Wilkie the expression of terror with the hands raised. ${ }^{2}$

\section{His contribution to medicine}

The book was a success. John Flaxman, professor of sculpture at the Royal Academy, thought it had done more for the arts than anything in the age. Henry Fuseli, who certainly knew about painting expression, thought highly of it, and Darwin gave it high praise when he wrote his work on expression in man and animals in 1872. Charles Bell hoped that the book, together with the warm recommendation of Astley Cooper, would help to lift him into the vacant chair of anatomy at the Royal Academy, because at that time he saw his future as an anatomist and illustrator. But that prig Sir Anthony Carlisle was appointed instead. Charles Bell had met Carlisle previously in

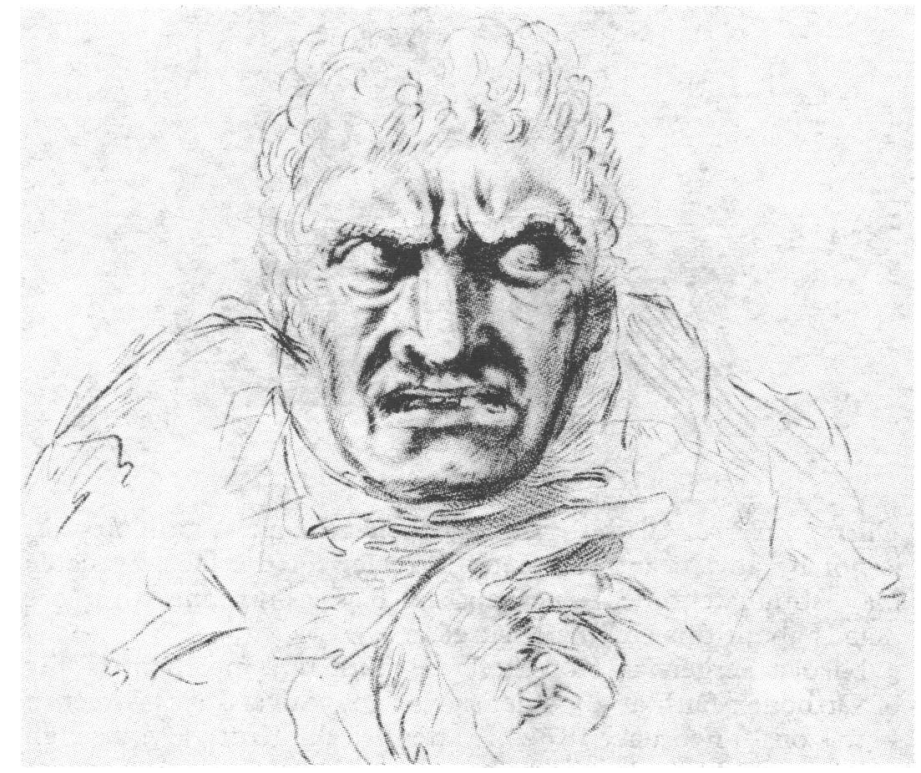

Suspicion or jealousy (p 136)

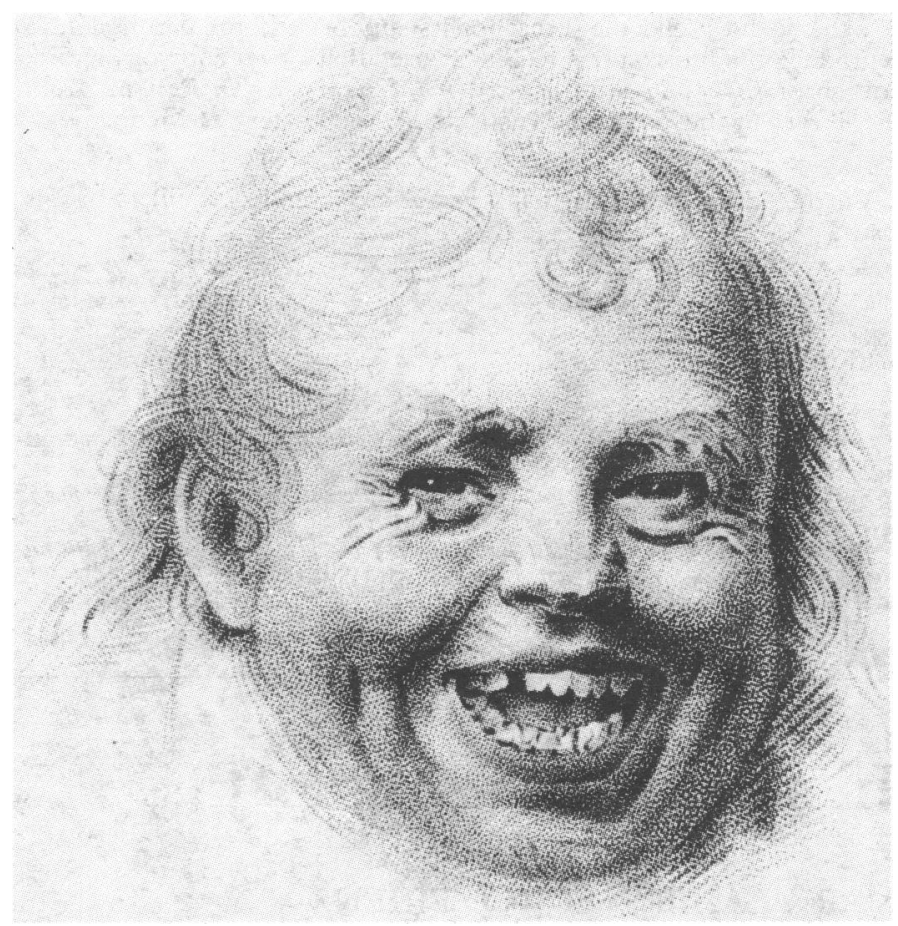

Laughter (p 125). This drawing was executed by the miniaturist Saunders, not by Charles Bell. Is there a suspicion of Hutchinson's teeth in this peculiarly ageless face?

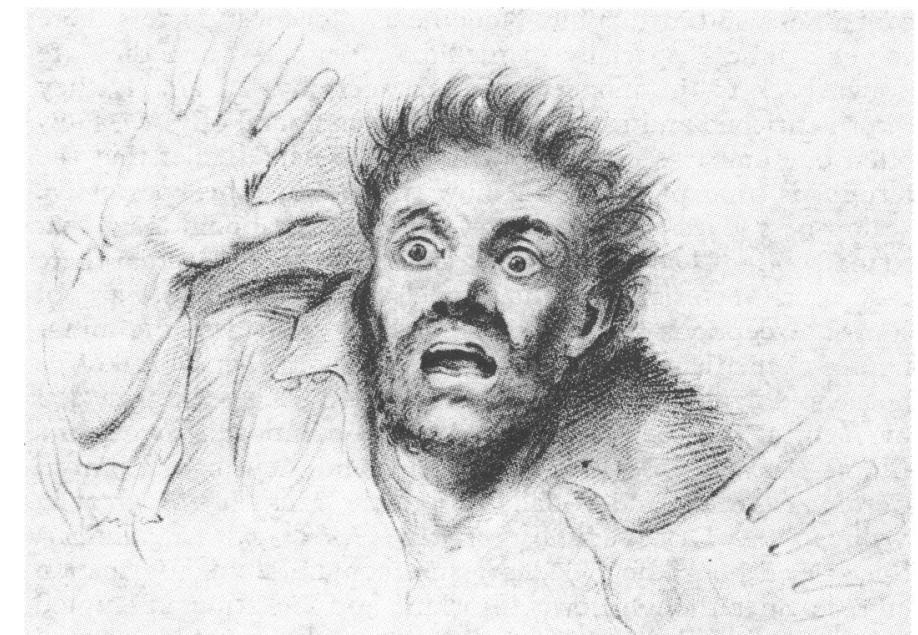

Fear mingled with wonder (p 142). This drawing is believed to be the work of David Wilkie.

December 1804 and wrote that he had "the greatest conceit of himself I ever knew a man to possess." 4

Charles Bell's subsequent career included his contributions to neurology, the founding of the Middlesex Hospital Medical School, and service to the wounded at Waterloo, which moved his pity immensely and left him with admiration for the private soldier and scorn for the thick-headedness of generals. Believing that London was a grand place to work in but a poor one to die in, he accepted the vacant chair of surgery in Edinburgh in 1836, which he held until his death in 1842. In fact he died at Hallow near Worcester while on his way to London and was buried in Hallow churchyard where, only hours before his death, he had sketched an old yew tree. Much has been written about Sir Charles Bell and the controversial subject of his contributions to neuroanatomy and neurophysiology. What is lacking is a comprehensive account of the artistic work of that unusually interesting and remarkable pair of Scottish surgeons, John and Charles Bell. 
I thank the Wellcome Trust for its support and for permission to reproduce the illustrations to Sir Charles Bell's own copy of the first edition of Essays on the Anatomy of the Expression in Painting from the library of the Wellcome Institute for the History of Medicine.

Further drawings from Bell's Essays are included as fillers in this issue.

\section{References}

${ }^{1}$ Bell JW. The Bells of Edinburgh. Surgery 1955;4:794-805.

${ }^{2}$ Gordon-Taylor G, Walls EW. Sir Charles Bell: his life and times. London: $\mathrm{E}$ and $\mathrm{S}$ Livingstone, 1958.

${ }^{3}$ Spillane JD. The doctrine of the nerves. Chapters in the history of neurology. Oxford: Oxford University Press, 1981:220.

+ Bell C. Letters of Sir Charles Bell selected from his correspondence with his brother, George foseph Bell. London: Murray, 1870.
${ }^{5}$ Anonymous. Lancet gallery of medical portraits: Sir Charles Bell. Lancet 1833;ii:756-61.

${ }^{6}$ Bell C. Engravings of the arteries illustrating the second volume of the anatomy of the human body and serving as an introduction to the surgery of the arteries. 3rd ed. London: Longmans, 1810.

${ }^{7}$ Bell C. A system of dissections. 1st ed. Edinburgh: Mundell and Son, 1798.

${ }^{8}$ Bell C. A series of engravings explaining the course of the nerves, plate II. London: Longman, 1803.

${ }^{9}$ Anonymous. Hunterian Oration of the Royal College of Surgeons, 1843. Lancet $1842-3 ; \mathrm{i}: 765-70$.

${ }^{10}$ Corner ER. Unpublished water-color sketches of Sir Charles Bell, with observations on his artistic qualities. Fohns Hopkins Hosp Bull 1914;25: 185-9.

${ }^{11}$ Bell C. Essays on the anatomy of the expression in painting. 1st ed. London: Murray, 1806. (Later entitled Essays on the anatomy and philosophy of the expression, 1824; and The anatomy and philosophy of expression as connected with the fine arts, 1893.)

12 Bell C. Essays on the anatomy and philosophy of expression. 2nd ed. London: Murray, 1824:141.

${ }^{13}$ Bell C. Essays on the anatomy and philosophy of expression. 2nd ed. London: Murray, 1824:71-2.

\title{
In search of Korotkoff
}

\author{
MARK LAHER, EOIN O'BRIEN
}

The influence of medical history on contemporary practitioners and on the course of medicine is as variable and subtle as it is contentious and ineluctible. Nonetheless, for most doctors there comes a time-especially in medical research-when they are drawn back to the pioneers of their specialty. Invariably they return enriched and refreshed from this temporal odyssey. How often one embarks on the journey in the naive belief that the terrain is unexplored, and how frequently this possessive zealousness gives way to mixed feelings of disappointment that so many others had travelled the same path, and relief that there is so much material to facilitate one's researches. There are, of course, exceptions but usually these are confined to the minor figures of medicine. Who would have thought that Korotkoff, a household name in clinical medicine, could have been neglected by medical historians? He is not even mentioned in Major's Classic Descriptions of Disease ${ }^{1}$; Willius and Keys ignore him in Cardiac Classics ${ }^{2}$; and he fails to join the ranks of the great in Willius and Dry's History of the Heart and Circulation. ${ }^{3}$ Specialised books on blood pressure contain scant information on the man, although Lewis, ${ }^{4}$ Ruskin, ${ }^{5}$ and Pickering ${ }^{6}$ attempted to redress the imbalance by publishing translations of his original paper from the Russian.

\section{Quest for Korotkoff}

Nicolai Korotkoff has, nonetheless, had one staunch champion. Harold Segall took up the cause back in 1939, and a series of interesting papers have appeared over the years. ${ }^{7-9}$ The first published photograph of Korotkoff appeared only in $1970^{10}$ and Segall produced another in $1976 .{ }^{9}$ These few papers provide us with the mere bones of biography; there is certainly no flesh, and hardly any sign of personality. Our own search for Korotkoff the man as well as the scientist brought us into a correspondence with Segall that provided tantalising pieces of information with the promise of better to come. Then in August 1980 we received one of a privately printed issue of the first translation of

Blood Pressure Clinic, Charitable Infirmary, and Department of Clinical Pharmacology, Royal College of Surgeons, Dublin

MARK LAHER, LRCPI, LRCSI, research registrar

EOIN O'BRIEN, FRCPI, consultant physician (cardiology)
Korotkoff's thesis ${ }^{11}$ and of even greater delight to us the edition included several unique photographs and a preface with biographical notes by Segall. The tortuous and prolonged research that makes this book so fascinating brings to mind The

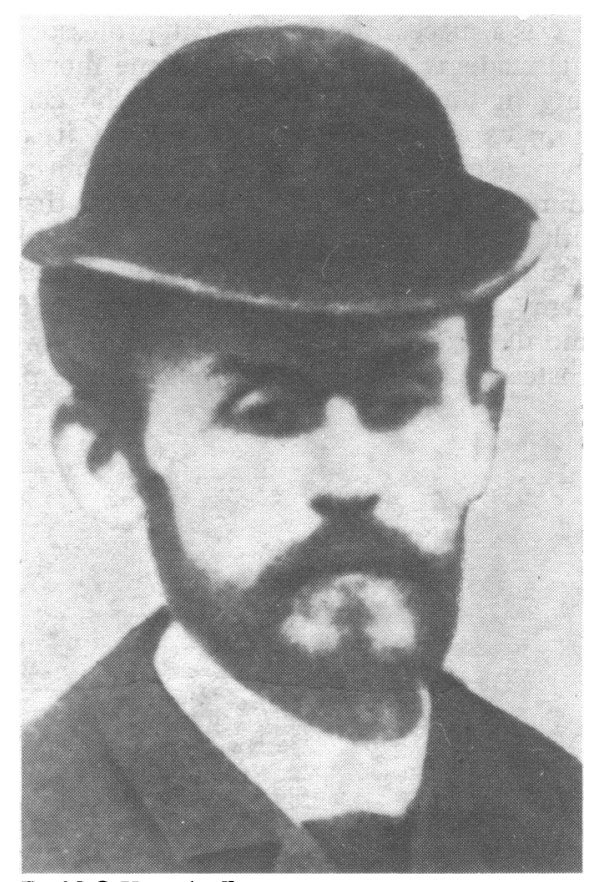

Dr N S Korotkoff.

Quest for Corvo, ${ }^{12}$ with the difference that the quest for Korotkoff is not by any means complete. A review of the facts available may stimulate others-perhaps in Russia-to unearth more details about this enigmatic surgeon.

Nicolai Sergeivich Korotkoff was born to a merchant family of Orthodox faith at 40 Milenskaya (now Sovetskaya) Street in Kursk on 13 February 1874. He attended the Kursk Gymnasium (secondary school), where he received excellent marks for behaviour and diligence but was found wanting in "divine 